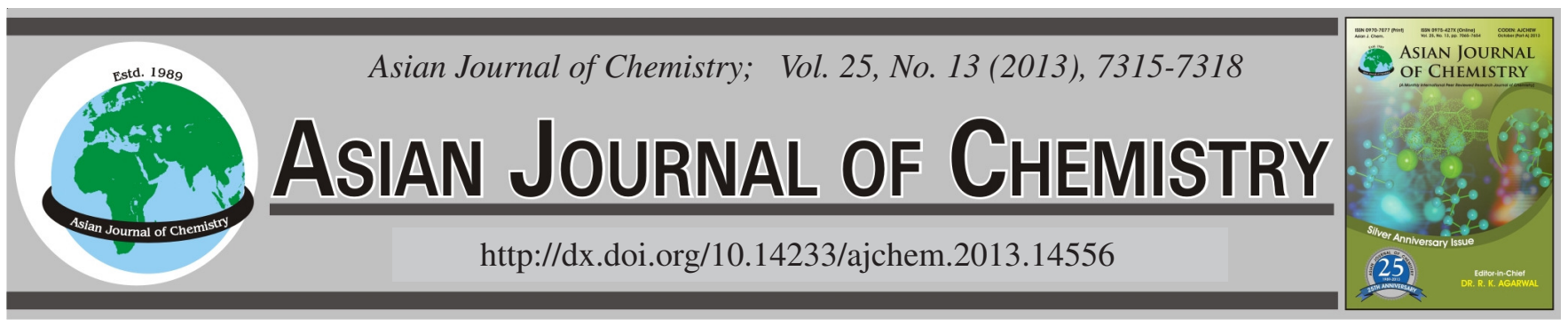

\title{
Determination of Trace Mercury in Cosmetics by Suspension- Sampling Hydride Generation Atomic Fluorescence Spectrometry
}

\author{
Shipeng Liu ${ }^{1}$, Pingring Zhang ${ }^{2}$, Hongchao Liu $^{1}$, Wei Wang ${ }^{1}$ and Kaoqi Lian ${ }^{1, *}$
}

${ }^{1}$ School of Public Health, Hebei Medical University, Shijiazhuang 050017, Hebei Province, P.R. China

${ }^{2}$ Institute of Basic Medicine, Hebei Medical University, Shijiazhuang 050017, P.R. China

*Corresponding author: E-mail: liankaoqi@126.com

(Received: 10 September 2012;

Accepted: 24 June 2013)

AJC-13698

\begin{abstract}
A method has been developed for the determination of mercury in cosmetics by suspension-sampling hydride generation atomic fluorescence spectrometry. About $500 \mathrm{mg}$ cosmetics, was mixed with absolute ethanol and agar solution. The samples were agitated with a vortex for $10 \mathrm{~min}$. The procedure permits the use of direct calibration for the determination of mercury in several cosmetic samples. The influences of instrument operating conditions, suspension preparation and interferences on the signals and the accuracy and precision were determined. The results for the reference cosmetic sample GBW09303a agreed satisfactorily with the certified values. The recoveries of the analytes varied in the range from 94 to $106 \%$. The detection limit was $2.4 \mathrm{ng} \mathrm{L}^{-1}$ of $\mathrm{Hg}$. The relative standard deviations were lower than $4.2 \%$, demonstrating a good precision for slurry analysis.
\end{abstract}

Key Words: Hydride generation, Suspension-sampling, Atomic fluorescence spectrometry, Mercury, Cosmetics.

\section{INTRODUCTION}

The high toxicity of mercury is well known to cause deleterious effects on the central nervous system in humans at low concentrations $^{1}$. The extremely high toxicity and ability to bioaccumulate in the environment are driving the need for analytical techniques providing high sensitivity and low detection limits.

Development of precise techniques applied to the determination of $\mathrm{Hg}$ in traces contributes greatly to the knowledge of the presence of $\mathrm{Hg}$ and risk to the environment and human health. The most widely used techniques for $\mathrm{Hg}$ determination include gas-diffusion (GD) ${ }^{2}$, atomic emission spectrometry $(\mathrm{AES})^{3}$, atomic absorption spectrometry $(\mathrm{AAS})^{4,5}$, atomic fluorescence spectrometry (AFS) $)^{6,7}$, inductively coupled plasma mass spectrometry (ICP-MS) ${ }^{8}$ and modified electrode $(\mathrm{ME})^{9}$, that recently have been suggested for determination of very low concentrations of $\mathrm{Hg}$ in water and biologic material. Considerably, less investigated were materials like cosmetics, which play a very important role in the modern life and is easily contaminated by additional quantities of $\mathrm{Hg}$.

The traditional pretreatment to dissolve the $\mathrm{Hg}$ species is a microwave digestion digestion procedure. However, this procedure is required adequate laboratory conditions and makes use of large quantities of glassware and reagents, increasing the risks of analyte contamination or loss. An alternative for the pretreatment is the suspension formation by using a vibrating and direct analysis of the solid suspension. Compared with traditional sample preparation methods, suspension formation combines the benefits of the solid and liquid sampling, avoiding the contamination and the loss of volatile elements and reduced sample amount needed. This mode has been extensively used in AAS ${ }^{10,11}$, ICP-MS ${ }^{12}$ and $\mathrm{AFS}^{13}$.

To our best of knowledge, no applications have been reported in the literature concerning the determination of $\mathrm{Hg}$ in cosmetics by suspension sampling with atomic fluorescence spectrometry. The main goal of this work was to develop new analytical methodologies based on the use of suspension sampling for fast and accurate determination of $\mathrm{Hg}$ in cosmetics by atomic fluorescence spectrometry. In this study, the instrument operating conditions, suspension preparation, suspension stability, acidity of the medium, accuracy and precision of the method had been optimized. Finally, data for different cosmetic samples were compared with those found after acid digestion, demonstrating that the proposed method was comparable with a traditional microwave digestion. This method was applied to the determination of $\mathrm{Hg}$ in reference material and some cosmetic samples.

\section{EXPERIMENTAL}

All solutions were prepared using doubly distilled water (DDW). The $1000 \mathrm{mg} \mathrm{L}^{-1}$ of $\mathrm{Hg}$ stock solution was purchased 
from the National Center for Analysis and Testing of Steel Materials. The working standards were obtained from the stock solution after dilution with $3 \%(\mathrm{v} / \mathrm{v}) \mathrm{HCl}$ prior to use. The $\mathrm{KBH}_{4}$ solutions of $7 \mathrm{~g} \mathrm{~L}^{-1}$ were daily prepared by dissolving proper amounts of $\mathrm{KBH}_{4}$ (Taihua Chemical Reagents Factory, Shanghai, China) in $0.5 \% \mathrm{NaOH}$ solution. High-purity absolute ethanol, $\mathrm{HCl}, \mathrm{HNO}_{3}, \mathrm{H}_{2} \mathrm{SO}_{4}, \mathrm{H}_{2} \mathrm{O}_{2}, \mathrm{NaOH}$ were also purchased from Kelong Chemical Reagents Factory. High purity $\operatorname{Ar}(99.99$ $\%$ ) was obtained from Shijiazhuang Gas Co. (Shijiazhuang, China). The certified reference samples from the National Research Center for Certified Reference Materials (Beijing, China).

A microwave-assisted chemical reactor consisting of a home-made cylindrical quartz container $(4.00 \mathrm{~cm} \times 1.50 \mathrm{~cm}$ o.d. $\times 1.25 \mathrm{~cm}$ i.d.) placed in a commercial microwave oven (WP800 T, Galanz Microwave Oven Wiring Co., Fuoshan, China), was constructed. Since microwave distribution is spatially dependent, the quartz container must aim at the magnetron of microwave oven wherein microwave irradiation was produced, to ensure the irradiation to focus on the reaction solution. An atomic fluorescence spectrometer (AFS-2202, Beijing Haiguang Instrument Co., Beijing, China) with hollow cathode lamps (Beijing Vacuum Electronics Research Institute, Beijing, China) was used for detection of $\mathrm{Hg}$. A schematic of the instrumentation was presented in Fig. 1. The instrumental parameters were in Table-1.

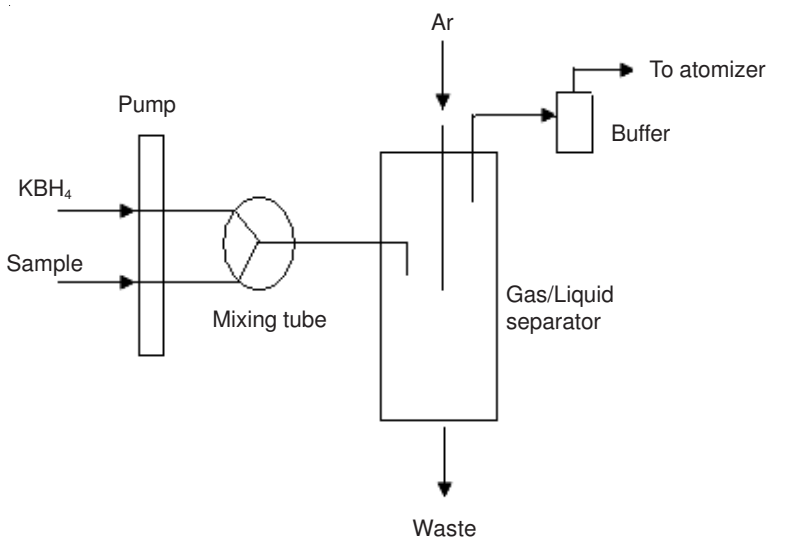

Fig. 1. Intermittent flow manifold

\begin{tabular}{|c|c|}
\hline \multicolumn{2}{|c|}{$\begin{array}{c}\text { TABLE-1 } \\
\text { PARAMETERS OF THE AFS INSTRUMENT }\end{array}$} \\
\hline Parameters & Conditions \\
\hline PTM voltage $(\mathrm{V})$ & 300 \\
\hline Atomizer temperature $\left({ }^{\circ} \mathrm{C}\right)$ & 200 \\
\hline Atomizer height $(\mathrm{mm})$ & 8.0 \\
\hline Lamp current (mA) & 20 \\
\hline Flow rate of carrier gas $(\mathrm{Ar})\left(\mathrm{mL} \mathrm{min}{ }^{-1}\right)$ & 500 \\
\hline Flow rate of shield gas $(\mathrm{Ar})\left(\mathrm{mL} \mathrm{min}{ }^{-1}\right)$ & 800 \\
\hline Read mode & Peak area \\
\hline Measure method & Std. curve \\
\hline Read time (s) & 7.0 \\
\hline Delay time (s) & 1.5 \\
\hline Read repeat (times) & 3 \\
\hline Injection volume (mL) & 0.5 \\
\hline
\end{tabular}

\section{Sample preparation and analytical procedure}

Suspension samples preparation: Suspension samples were prepared by accurately weighing $500 \mathrm{mg}$ cosmetic sample in $25 \mathrm{~mL}$ glass flasks and adding $3 \mathrm{~mL}$ absolute ethanol, mix thoroughly, then diluted to the mark with $1.5 \mathrm{~g} \mathrm{~L}^{-1}$ agar solution. The resulting suspensions were dispersed with a vortex for $10 \mathrm{~min}$ in order to obtain homogeneous dispersions. The standard solutions, in which the concentration of $\mathrm{Hg}$ varied from $0-2 \mu \mathrm{g} \mathrm{L}^{-1}$ were prepared by the above mentioned procedure and used for calibration.

Microwave digestion: To determine $\mathrm{Hg}$, ca $0.5 \mathrm{~g}$ of cosmetic sample was accurately weighed inside a pressureresistant vessel $(100 \mathrm{~mL})$ and was digested with $4 \mathrm{~mL}$ of $69 \%$ concentrated nitric acid, $2 \mathrm{~mL}$ of $35 \%$ hydrogen peroxide and $4 \mathrm{~mL}$ of $\mathrm{H}_{2} \mathrm{O}$. The mixture was sonicated for $0.5 \mathrm{~h}$ in an ultrasound water bath and the reactor was closed, starting the digestion procedure in a microwave oven following the program: step 1-room temperature to $80^{\circ} \mathrm{C}$ for $3 \mathrm{~min}$; step 2heat $80-140^{\circ} \mathrm{C}$ for $9 \mathrm{~min}$; step 3 - heat $140-180{ }^{\circ} \mathrm{C}$ for $4 \mathrm{~min}$; step 4- hold at this temperature for $15 \mathrm{~min}$; step 5- decrease the temperature to $30{ }^{\circ} \mathrm{C}$ for $25 \mathrm{~min}$. After cooling the vessels to room temperature, sample and blank digests were diluted to $25 \mathrm{~mL}$ with double distilled water.

Analytical procedure: Total $\mathrm{Hg}$ in the sample suspension and the standard solutions were merged with $\mathrm{KBH}_{4}$ to form the hydrides. The analytes were determined by atomic fluorescence spectrometry under the optimized experimental conditions.

\section{RESULTS AND DISCUSSION}

Effects of flow rate of carrier gas: Argon was used as carrier gas to bring $\mathrm{Hg}$ vapour from liquid phase to gas phase. The effect of argon flow rate on detection of $\mathrm{Hg}$ was studied from 200 to $800 \mathrm{~mL} \mathrm{~min}^{-1}$. At $200 \mathrm{~mL} \mathrm{~min}^{-1}$, the baseline was not stable. Better baseline could be obtained by increasing the argon gas flow. Increasing the flow rate of the carrier gas, the intensity of $\mathrm{Hg}$ decreased slightly, owing to dilution and shorter residence time of $\mathrm{Hg}$ vapour in the atomizer. An argon carrier gas flow rate of $500 \mathrm{~mL} \mathrm{~min}{ }^{-1}$ was chosen as an optimized condition.

Effects of suspension medium: Suspension preparation in aqueous solution is rarely suitable because most powdered materials undergo rapid sedimentation. This sedimentation of suspended material usually occurs after mixing the suspension. The sedimentation rate depends on the densities of the diluent and solid material, the viscosity of the diluent medium and the radius of the sample particles. The suspension can be stabilized using a highly viscous liquid medium. So far, agar, glycerol and Triton-x100 have been used as suspension stabilizing agents. In this study, the results showed that the viscosity of agar kept different types of particles in suspension for a sufficient time. Furthermore, it has been stated that the optimum concentration of agar was $1.5 \mathrm{~g} \mathrm{~L}^{-1}$ for the homogenization of suspension cosmetics samples. Therefore, in the present work, $1.5 \mathrm{~g} \mathrm{~L}^{-1}$ agar solution is used as the suspension stabilizing agent.

Effects of $\mathrm{KBH}_{4}$ concentrations: The $\mathrm{KBH}_{4}$ concentration is a major factor that has a strong and definitive effect on the performance of hydride generation. The effect of the $\mathrm{KBH}_{4}$ concentration was investigated from $4-10 \mathrm{~g} \mathrm{~L}^{-1}$ in a $0.5 \% \mathrm{NaOH}$ medium. Fig. 2 shows the atomic fluorescence spectrometry signal variation versus $\mathrm{KBH}_{4}$ concentration. The results indicate 


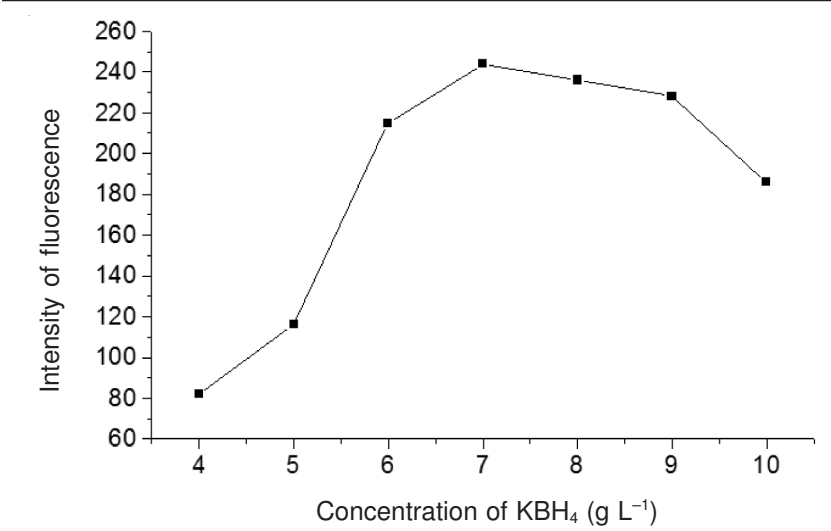

Fig. 2. Effect of $\mathrm{KBH}_{4}$ concentrations. Carrier solution, $4 \%(\mathrm{v} / \mathrm{v}) \mathrm{HCl}$; $\mathrm{Hg}$ solution, $0.5 \mathrm{~g} \mathrm{~L}^{-1}$ in $3 \%(\mathrm{v} / \mathrm{v}) \mathrm{HCl}$

that the signal goes up with increasing potassium borohydride concentration up to $7 \mathrm{~g} \mathrm{~L}^{-1}$. It can be concluded that the introduction of an increasing amount of $\mathrm{H}_{2}$ to the discharge enhanced the atomization efficiency of hydrides as a result of the higher thermal conductivity of $\mathrm{H}_{2}$ as compared to Ar and the relatively high dissociation temperature of $\mathrm{H}_{2}$. However, the signals either remain constant or even decrease for further increase in $\mathrm{KBH}_{4}$ concentration, probably due to a continuously increasing dilution of the analyte by the generated hydrogen and the reduced residue time of the analyte species in the atomizer. Therefore, a $\mathrm{KBH}_{4}$ concentration of $7 \mathrm{~g} \mathrm{~L}^{-1}$ was the optimum condition for the detection of $\mathrm{Hg}$.

Effects of acidity: Acidity of the solution is an important parameter that has great influence on the hydride generation and even critic. In this study, the acidic medium concentration effects of $\mathrm{H}_{2} \mathrm{SO}_{4}, \mathrm{HNO}_{3}$ and $\mathrm{HCl}$ on $\mathrm{Hg}$ hydride generation were investigated. The results were presented in Fig. 3. Fig. 3 showed that the $\mathrm{Hg}$ signal intensity of $\mathrm{HCl}$ system was much higher than $\mathrm{HNO}_{3}$ and $\mathrm{H}_{2} \mathrm{SO}_{4}$ systems. So $4 \%$ (v/v) $\mathrm{HCl}$ was the most suitable acidity.

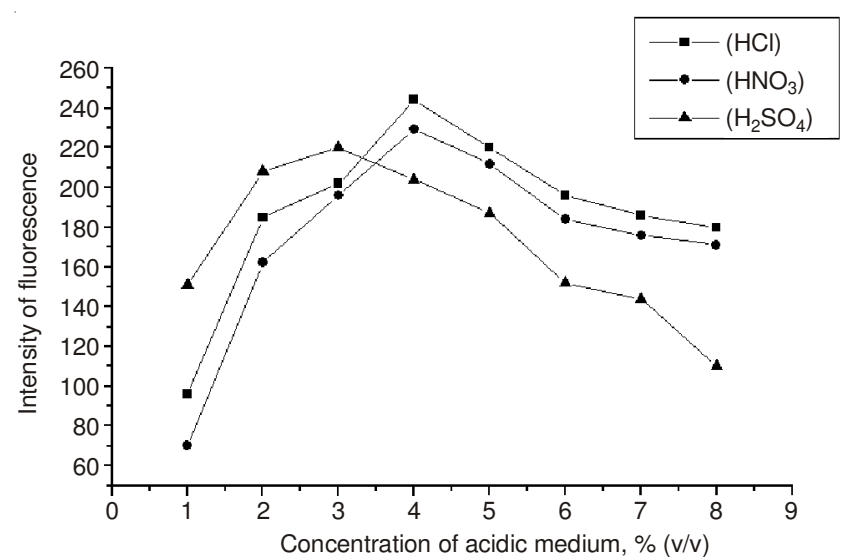

Fig. 3. Effect of acidic medium concentration. Reductant solution, $7.0 \mathrm{~g}$ $\mathrm{L}^{-1} \mathrm{KBH}_{4} ; \mathrm{Hg}$ solution, $0.5 \mathrm{~g} \mathrm{~L}^{-1}$ in $3 \%(\mathrm{v} / \mathrm{v}) \mathrm{HCl}$

Effects of absolute ethanol: The addition of absolute ethanol leads to a more uniform distribution of cosmetics in agar solution and it could eliminate gas bubbles in the procedures of solution preparing and instrument detecting. The effect of the absolute ethanol concentration was investigated from 1 to $5 \mathrm{~mL}$ in a $0.5 \% \mathrm{NaOH}$ medium. The results indicate that the signal goes up with increasing potassium borohydride concentration up to $3 \mathrm{~mL}$. However, the signals decrease for further increase in absolute ethanol concentration. Therefore, an absolute ethanol concentration of $3 \mathrm{~mL}$ was the optimum condition for the detection of $\mathrm{Hg}$.

Interference studies: The major drawbacks of hydride generation are the interferences caused by the transition elements and notable metals, especially $\mathrm{Fe}, \mathrm{Co}, \mathrm{Ni}$ and $\mathrm{Cu}$, because their metallic state and colloidal forms are formed in $\mathrm{KBH}_{4}$ solution. $0.2 \mathrm{~g} \mathrm{~L}^{-1}$ of $\mathrm{Hg}$ with a mixture solution containing a certain amount of $\mathrm{Fe}, \mathrm{Co}, \mathrm{Ni}$ and $\mathrm{Cu}$ were determined, respectively. The results of these experiments suggested no significant interference was observed, even at concentration as high as $10 \mathrm{mg} \mathrm{L}^{-1}$ for $\mathrm{Fe}, 8 \mathrm{mg} \mathrm{L}^{-1}$ for $\mathrm{Co}$ and $\mathrm{Cu}$ and $1 \mathrm{mg} \mathrm{L}^{-1}$ for $\mathrm{Ni}$.

Analytical performance: A successive measurement of a $0.2 \mu \mathrm{g} \mathrm{L} \mathrm{L}^{-1}$ of $\mathrm{Hg}$ solution gave a RSD of $3.5 \%$ for 11 runs, which indicated good reproducibility of the proposed method. The analysis of a series solutions containing 0.0, 0.20, 0.50, $1.00,1.50,2.00 \mu \mathrm{g} \mathrm{L}^{-1}$ of $\mathrm{Hg}$, respectively, gave a calibration function of $\mathrm{I}_{\mathrm{f}}=-12.6+512.3 \mathrm{X}\left(\mathrm{I}_{\mathrm{f}}\right.$, the signal intensity and $\mathrm{X}$, the concentration of $\mathrm{Hg}$, expressed in $\mu \mathrm{g} \mathrm{L}^{-1}$ ), of which the correlation coefficient is 0.9992 .

The detection limits (DL) for $\mathrm{Hg}$ species was evaluated on the basis of the standard deviation (SD) of the measured signals (11 times) for the blank solution and was calculated by the formulate $\mathrm{DL}=3 \mathrm{SD} \mathrm{K}^{-1}$ (here $\mathrm{K}$ is the slopes of the calibration graph). As results, the detection limits was $2.4 \mathrm{ng} \mathrm{L}^{-1}$.

Cosmetic samples analysis: In order to demonstrate the reliability of the proposed differential method, it was applied to the determination of total $\mathrm{Hg}$ in the standard reference materials of GBW09303a and the analytical results are listed in Table-2. The results indicate that the $\mathrm{Hg}$ contents in the standard reference materials, determined by the present method, were consistent with the reference values. The proposed method was also applied to the determination of $\mathrm{Hg}$ in some cosmetic samples. The results are given in Table-3. In order to examine any systematic errors associated with the determination, recovery of $\mathrm{Hg}$ spikes was measured and the sample preparation method was compared with microwave digestion. Results from the developed method were in good agreement with those obtained after microwave digestion. The recoveries of $\mathrm{Hg}$ were in the range 94-106 \%. The RSD was from 2.8 to $4.2 \%$. This is indicative of excellent recovery of $\mathrm{Hg}$.

TABLE-2

ANALYSIS OF STANDARD REFERENCE MATERIALS

\begin{tabular}{ccc}
\hline Sample & Certified $\left(\mu \mathrm{g} \mathrm{g}^{-1}\right)^{\mathrm{a}}$ & Found $\left(\mu \mathrm{g} \mathrm{g}^{-1}\right)^{\mathrm{a}}$ \\
\hline GBW09303a & $1.33 \pm 0.06$ & $1.32 \pm 0.04$ \\
\hline${ }^{\mathrm{a}}$ Means and standard deviations from 7 replicate measurements.
\end{tabular}

\section{Conclusion}

The developed procedure offered a simple and convenient alternative to those based on a previous complete digestion of samples for the determination of $\mathrm{Hg}$ in cosmetics. This method, based on the excellent sensitivity attainable by atomic fluorescence spectrometry and on a soft room-temperature treatment 
TABLE-3

RESULTS FROM DETERMINATION OF MERCURY IN COSMETIC SAMPLES ${ }^{\mathrm{a}}$

\begin{tabular}{ccccccc}
\hline Sample & Found $\left(\mu \mathrm{g} \mathrm{g}^{-1}\right)$ & RSD $(\%)$ & Added $\left(\mu \mathrm{g} \mathrm{g}^{-1}\right)$ & Total $\left(\mu \mathrm{g} \mathrm{g}^{-1}\right)$ & Recovery $(\%)$ & Microwave digestion $\left.(\mu \mathrm{g} \mathrm{g})^{-1}\right)$ \\
\hline 1 & 1.62 & 2.8 & 1.50 & 3.09 & 98 & 1.63 \\
2 & - & - & 0.50 & 0.52 & 104 & - \\
3 & 0.28 & 4.2 & 0.50 & 0.75 & 94 & 0.27 \\
4 & 0.53 & 3.8 & 0.50 & 1.01 & 96 & 0.55 \\
5 & - & - & 0.50 & 0.53 & 106 & - \\
\hline
\end{tabular}

${ }^{\mathrm{a}}$ Means and standard deviations from 5 replicate measurements.

of the samples, was a safe and comfortable methodology for operators, which reduced the reagent consumption and time of analysis and offered a possibility to explore the presence of mercury in cosmetics. The developed method was simple and accurate, so the method was promising for routine analysis of trace of $\mathrm{Hg}$ in other more complex materials.

\section{REFERENCES}

1. J.J.B. Nevado, R.C.R. Martín-Doimeadios and M.J. Moreno, Microchem. J., 93, 12 (2009).

2. N. Amini, T.J Cardwell and R.W. Cattrall, Talanta, 63, 1069 (2004).

3. L. Hakim, A. Sabarudin, K. Oshita and M. Oshima, Talanta, 76, 1256 (2008).
4. H. Ashkenani, S. Dadfarnia, A.M.H. Shabani and A.A. Jaffari, J. Hazard. Mater, 161, 176 (2009).

5. B. Welz, D.L. Tsalev and M. Sperling, Anal. Chim. Acta, 261, 91 (1992).

6. X.J. Jiang, W.E. Gan, L.Z. Wan and H.C. Zhang, Spectrochim. Acta B, 65, 171 (2010).

7. G. Vermeir, C. Vandecasteele and R. Dams, Anal. Chim. Acta, 242, 203 (1991).

8. R. He, J. Chen, Z.J. Huang and J.Y. Yin, Asian J. Chem., 19, 1085 (2007).

9. A.A. Ensafi, A.R. Allafchian, M. Saraji and B. Farajmand, Talanta, 99, 335 (2012).

10. Z. Slovák and B. Docekal, Anal. Chim. Acta, 129, 263 (1981).

11. W.C. Tseng, P.H. Chen, T.S. Tsay and B.H. Chen, Anal. Chim. Acta, 576, 2 (2006).

12. G.A. Zachariadis and A.F. Olympiou, J. Pharm. Biomed. Anal., 47, 541 (2008).

13. P. Cava-Montesinos, M.L. Cervera and A. Pastor, Talanta, 62, 173 (2004). 